\title{
PEER ASSESSMENT AS COLLABORATIVE LEARNING: A COGNITIVE PERSPECTIVE
}

This is a post-print of an article submitted for consideration in the Learning and Instruction (C) 2010 Elsevier.

Personal use of this manuscript is permitted. Permission from Elsevier must be obtained for any other commercial purpose.

This article may not exactly replicate the published version, due to editorial changes and/or formatting and corrections during the final stage of publication. Interested readers are advised to consult the published version which can be found at:

http://www.sciencedirect.com/science/article/pii/S0959475209000772

doi:\{10.1016/j.learninstruc.2009.08.005\}

Please refer this manuscript as:

Kollar, I. \& Fischer, F. (2010). Peer assessment as collaborative learning: a cognitive perspective. Learning and Instruction, 20(4), 344-348. 
Running head: Peer assessment as collaborative learning

\title{
Commentary
}

Peer assessment as collaborative learning: A cognitive perspective

$$
\text { Ingo Kollar*, Frank Fischer }
$$

Chair of Empirical Education and Educational Psychology, Ludwig-Maximilians-University, Leopoldstrasse 13, D-80802, Munich, Germany

\begin{abstract}
Peer assessment is an important component of a more participatory culture of learning. The articles collected in this special issue constitute a representative kaleidoscope of current research on peer assessment. In this commentary, we argue that research on peer assessment is currently in a stage of adolescence, grappling with the developmental tasks of identity formation and affiliation. Identity formation may be achieved by efforts towards a shared terminology and joint theory building, whereas affiliation may be reached by a more systematic consideration of research in related fields. To reach identity formation and affiliation, preliminary ideas for a cognitively toned, process-related model of peer assessment and links to related research fields, especially to research on collaborative learning, are presented.
\end{abstract}

Keywords: Peer assessment; Collaborative learning; Cognitive processes; Discursive processes.

* Corresponding author. Tel.: +49 892180 6888; fax: +49 892180996888.

E-mail address: ingo.kollar@psy.lmu.de (I. Kollar) 


\section{Introduction}

Peer assessment is an important component in the design of learning environments implementing a more participatory culture of learning. This special issue presents systematic conceptual and empirical research on this highly relevant phenomenon. We consider the present special issue as a real milestone as the collected articles are among the first successful efforts to systematically address peer assessment by using (quasi-)experimental research methodologies that allow for an identification of crucial characteristics, components and effects of peer assessment practices. While Van Zundert, Sluijsmans, and Van Merriënboer (THIS ISSUE) provided a comprehensive overview on current research on peer assessment, the remaining five articles represent exemplary empirical studies on some of the distinctive conditions, processes and effects of peer assessment. Van Gennip, Segers, and Tillema (THIS ISSUE) investigated the effects of peer assessment on interpersonal variables such as psychological safety, interdependence and trust. Strijbos, Narciss, and Dünnebier (THIS ISSUE) examined the effects of different types of feedback and the (perceived) sender's competence level on feedback perception and performance in subsequent revision. When investigating by what mechanisms the efficiency of feedback on learning is mediated, Gielen, Peeters, Dochy, Onghena, and Struyven (THIS ISSUE) demonstrated that feedback needs to be well justified to have a positive effect on learning. A scaffolding perspective was adopted by Van Steendam, Rijlaarsdam, Sercu, and Van den Bergh (THIS ISSUE) who investigated whether a revision strategy is better acquired through observation or practising and whether its' application is better achieved individually or collaboratively. Finally, Cho and MacArthur (THIS ISSUE) examined different feedback types, their relation to revision performance and the effects of having multiple peers assessing a students' work compared to a single student or expert. Each of the presented studies deserves credit for clarity in presentation, creativity and thoughtfully approaching their specific research questions and using advanced statistical methods.

However, as Van Zundert et al. (THIS ISSUE) demonstrated in their literature review, there are not many empirical studies on peer assessment that adhere to a (quasi-)experimental methodology and thus can shed light on how best to design peer assessment in educational contexts. Borrowing terminology from developmental sciences, research on peer assessment may be located in the developmental stage of adolescence. During infancy, it has successfully gone through the development of basic operations and developed its own unique character, but now it faces two questions connected to "developmental tasks" that are typical for adolescence: "Who am I?" and "Who are my peers?" The first question may be conceptualised as the developmental task of identity formation, and the second one as the developmental task of affiliation.

\section{Identity formation and affiliation of research on peer assessment}

That identity formation is a pressing task for research on peer assessment becomes manifest in that there is (a) a diversity in terminology used in the collected articles to describe the phenomenon of peer assessment and (b) a lack of a commonly agreed-upon process model of what overt processes constitute peer assessment and what cognitive and discursive processes are associated with these overt activities (cf. the "need for functional development"; Strijbos \& Sluijsmans, THIS ISSUE). Concerning terminology, it is remarkable that while Van Gennip et al. (THIS ISSUE) and Van Zundert et al. (THIS ISSUE) are talking about "peer assessment", Van Steendam et al. (THIS ISSUE) as well as Cho and MacArthur (THIS ISSUE) use "peer revision" to describe the phenomenon. Yet differently, Gielen et al. (THIS ISSUE) and Strijbos et al. (this issue) introduce "peer feedback" when describing the topic of their research. One may argue that this variety simply reflects that the authors investigate 
different sub-processes or sub-phenomena of peer assessment. This certainly is true with respect to characteristics (e.g., validity, accuracy and reliability of peer assessment; Gielen et al., THIS ISSUE), conditions (e.g., scaffolding as realized in Van Steendam et al., THIS ISSUE) and outcomes of peer assessment (e.g., peer assessment skills or learning performance; Strijbos et al., THIS ISSUE; Van Zundert et al., THIS ISSUE). However, concerning the central processes and activities of peer assessment, this does not appear true. Clearly, a model that specifies the overt activities (such as "feedback provision" or "feedback reception") and connected cognitive and discursive processes of peer assessment and their relation to learning is missing.

That affiliation is a second important task for research on peer assessment becomes apparent in that it still seems to be unsure who its closest peers - in terms of related research fields - are (cf. the "need for conceptual development"; Strijbos \& Sluijsmans, THIS ISSUE). Research on peer assessment could clearly benefit much from knowledge gathered in related fields such as peer tutoring (Graesser, Person, \& Magliano, 1995), help seeking (Aleven, Stahl, Schworm, Fischer, \& Wallace, 2003) and collaborative learning (Webb \& Farivar, 1999). In fact, peer assessment is fundamentally a collaborative activity that occurs between at least two peers. When acknowledging this, one crucial issue is the degree of interactivity that is permitted during peer assessment (see also Strijbos, Ochoa, Sluijsmans, Segers, \& Tillema, 2009). In the articles collected here, very often there was quite a clear-cut differentiation between an "assessee" and an "assessor", with particular activities such as "providing feedback" or "revising" connected to each of these roles and rather low levels of interactivity in terms of highly frequent exchange between the learning partners. In a more interactive version, however, peer assessment may permit or even require peers to negotiate about how to approach the given task, how to give feedback and how to use feedback during revision. Such interactive exchange may be beneficial because it may evoke cognitive and discursive processes that trigger a deeper elaboration of the material and, thus, lead to better learning (King, 2007).

Our commentary is meant to provide some "educational guidance" for research on peer assessment to solve the developmental tasks of identity formation and affiliation. This "educational guidance" will be laid out in two steps. First, we will introduce a sight structure model of peer assessment that distinguishes four main activities that constitute a prototypical peer assessment scenario. Second, we will illustrate what cognitive and discursive processes need to be performed during each of these activities to leverage the potential of peer assessment concerning the participants' learning. In doing so, we will refer to insights from different strands of cognitively oriented research on learning and instruction, but especially from research on collaborative learning.

\section{Supporting identity formation and affiliation: Developing a cognitively oriented process model of peer assessment}

In approaching the two developmental tasks, we recommend to develop a cognitively toned process model of peer assessment. In developing such a model, we consider it useful to first think about the "sight structure" (Oser \& Baeryswil, 2001) of peer assessment. Therefore, we will first describe four rather overt activities that typically occur during peer assessment. Subsequently, we will lay out what cognitive and discursive processes need to occur during these four overt activities to make peer assessment a successful event and discuss to what extent more interactive variants of peer assessment may be useful to evoke these processes. For reasons of simplicity, we will emanate from a dyadic representation of peer assessment, labelling the learning partners " $\mathrm{A}$ " and " $\mathrm{B}$ " in the following sections.

\subsection{The sight structure of peer assessment}


Peer assessment typically starts with a task performance. For example, A may be asked to write a letter-to-the-editor (see Gielen et al., THIS ISSUE) or solve a mathematical problem. In the present studies, task performance has mainly been realised as an individual activity, that is, individual learners were asked to solve a given task. An exception is the study by Van Gennip et al. (THIS ISSUE), in which teams of students were supposed to collaboratively build a robot artefact. Yet, this study did not investigate whether interactivity during task performance was helpful compared to individual task performance. Gaining insight into how exactly the teams collaborated (e.g., examining their discourse processes) and experimentally comparing this to individuals working on the same task would be informative to judge whether interactivity during task performance leads to higher learning gains than individual task performance.

A second activity in peer assessment is feedback provision, during which B assesses the quality of A's task performance. Here, at least two issues become crucial. First, the actual object for feedback needs to be determined: is it (a) the product of A's task performance (e.g., a letter-to-the-editor; see Gielen et al., this issue) or (b) the process by which A arrived at that product (e.g., the observable activities when writing that letter)? In the present articles, feedback was mainly given on products rather than on processes. It would be interesting whether feedback on processes of task performance evokes different cognitive processes than assessing the end product. Second, the mode in which feedback is provided may also be subject to variation. For example, B may be asked to give an overall quality rating on a 5point Likert-type scale (Cho \& MacArthur, THIS ISSUE), to produce a text in which to list the problems in A's task performance (Gielen et al., THIS ISSUE), or - referring to the interactivity issue - to discuss weaknesses in A's task performance in an interactive fashion. Although most of the articles collected in this special issue excluded such direct exchange between the feedback sender and feedback receiver, allowing A to ask clarification questions on B's feedback or give justifications on the first task performance could lead to higher learning outcomes.

A third activity in peer assessment is feedback reception. Under less interactive circumstances, A listens to or reads B's comments/assessments on the initial task performance with no opportunities to communicate about this feedback. In most of the empirical studies collected in this special issue, this was the case. In a more interactive realisation of peer assessment, such exchange may be allowed or even demanded. A good example is the study by Gielen et al. (THIS ISSUE), in which students in one condition were allowed to reply to their peers' feedback. It may well be that A does not fully understand B's criticisms and that further clarification is needed. Purposefully allowing such feedback dialogue may positively influence the success of peer assessment, if this dialogue involves high-level cognitive and discursive processes.

Typically, the final activity in peer assessment is revision. In a less interactive realisation, A is working over the first task performance on the basis of B's feedback. In a more interactive mode, this could be a joint activity, in which A and B work together with the joint goal to improve the demanded product or process. Whether revision should be performed as an individual or a collaborative task has been addressed by Van Steendam et al. (THIS ISSUE), showing that collaboration is useful for the quality of revision as long as it is preceded by observing a model in the application of a peer assessment strategy. Perhaps there are more conditions under which more interactive revision process is more helpful for learning than less interactive revision process. Further studies on that issue are needed.

\subsection{Cognitive and discursive processes during peer assessment activities}


Simple engagement in task performance, feedback provision, feedback reception, and revision does not automatically mean that "learning" takes place. In fact, any of the four activities can be performed weakly. When learning is seen as high-level change in an individual's knowledge base, then, to make peer assessment a successful enterprise, it is necessary that high-level cognitive processing occurs. This, in turn, may possibly be facilitated through more interactive forms of peer assessment. In the following, we provide examples of such high-level cognitive and discursive processing in each of the four presented activities of peer assessment.

\subsubsection{High-level cognitive and discursive processing during task performance}

During task performance, what counts as high-level cognitive processes varies by the type of task. Research on text production, for example, shows that successful writing depends on (meta-)cognitive processes such as planning, translating and reviewing (Hayes \& Flowers, 1980). Successful engagement in mathematical problem-solving has been demonstrated to depend on self-explanation (Renkl, 1997) and the use of heuristic strategies (Schoenfeld, 1985). When task performance is conducted more interactively, discursive processes such as explaining (Webb, 1989), arguing (Andriessen, Baker, \& Suthers, 2003) or questioning (King, 1997) may facilitate high-level cognitive processing. Thus, interactively engaging in a task may be beneficial in terms of evoking higher-order cognitive processes which in turn should be positively related to individual learning outcomes.

\subsubsection{High-level cognitive and discursive processing during feedback provision}

For B's feedback to facilitate A's learning, B not only needs to deeply process A's first product, but also show planning and monitoring concerning how to formulate feedback in a way that A can benefit from it. If feedback provision is conducted in a more interactive mode, a typical problem is that learners often show suboptimal help-seeking behaviour (Aleven et al., 2003). For example, A may not feel competent to perform a task and therefore simply ask B for the right solution - executive help (Aleven et al., 2003) or knowledge of correct result (Hattie \& Timperley, 2007). Yet, research on help seeking (Aleven et al., 2003) has shown that more instrumental help, that is, help that supports $\mathrm{A}$ in solving the task independently, is connected to higher learning gains in contrast to asking and receiving executive help which is not. This is corroborated by findings from the feedback literature showing that knowledge of result feedback is usually less effective than elaborated feedback (see Hattie \& Timperley, 2007). However, Strijbos et al.'s (THIS ISSUE) findings that elaborated specific feedback may sometimes be less effective than general concise feedback warrant caution towards preferring elaborated feedback under all circumstances.

Research on common ground (Clark \& Brennan, 1991) has moreover demonstrated that it is sometimes difficult for B to assess A's level of expertise and design the feedback in a way that A can easily understand it. Sometimes, peers may even have more accurate knowledge of the comprehension problems than teachers and in some cases even communicate their feedback more effectively because they have a vocabulary that can be more easily understood by their peers (see Van Zundert et al., THIS ISSUE). More interactive situations in which further exchange between two learning partners is allowed may be helpful for materialising such more balanced communication.

\subsubsection{High-level cognitive and discursive processing during feedback reception}

In a recent empirical study, Van der Pol, Van den Berg, Admiraal, and Simons (2008) have argued that for peer feedback to facilitate learning, one crucial condition is that the feedback is taken up by the receiver. Yet, the uptake of feedback is very likely only positively related to learning when the feedback is relevant and of high-enough quality - and when A has recognised this. Given that B provided relevant, high-quality feedback, then the cognitive 
processes A needs to engage in are to thoroughly examine B's feedback, compare the first task performance with B's suggestions, and decide whether following B's suggestions is useful to improve the initial task performance. Again, interaction during feedback reception may be advantageous. For example, asking thought-provoking questions such as "What evidence is there to support the contention that ..." has been shown to contribute to higher learning (see King, 2007). If such questions are asked during feedback reception, A is triggered to engage in high-level cognitive processes to arrive at satisfactory explanations. Likewise, research on argumentation suggests that A will likely engage in high-level cognitive processes when B provides well-warranted counterarguments to A's arguments in the first task performance, and that these may be the starting point for an argumentation event that in the end facilitates learning of both learners (Leitão, 2000). Socio-cognitive perspectives, in turn, suggest that "socio-cognitive conflicts" which may arise in such situations may evoke significant cognitive change, but only when it is successfully resolved (Nastasi \& Clements, 1992).

\subsubsection{High-level cognitive and discursive processing during revision}

If B's feedback is of a high quality and A has recognised that, revising poses a high load on A's thinking processes. If feedback has been given on a product, A needs to perform comparison processes between this first product, B's feedback and the (possible) revision. Also, coherently integrating someone else's suggestions into one's own product can be a demanding process. Allowing for communication during revision may greatly alleviate comparison and integration processes since the burden of revision is distributed over the two learning partners so that cognitive load may be diminished (e.g., by having A do the revision and $\mathrm{B}$ monitor and intervene). However, giving opportunities for exchange during revision may also be harmful because B may interrupt A's thinking processes. To judge whether interactivity during the revision process has positive effects on individual learning, further studies are needed.

\section{Concluding remarks}

We started this commentary by locating research on peer assessment in a stage of adolescence, facing the two developmental tasks of identity formation and affiliation. To solve the identity formation task, we argued that it would be helpful to develop a shared language on central processes and activities of peer assessment and put effort in developing a commonly-agreed upon, cognitively toned model of peer assessment and have offered some first thoughts in that direction. To solve the affiliation task, we suggested research on peer assessment to more strongly reflect on its relation to other fields of research such as collaborative learning, help seeking and argumentation. As illustrated, stronger ties to collaborative learning research may greatly inform theory building and empirical research on peer assessment. This is however not meant to discredit less interactive variants of peer assessment as they dominate in the articles collected in this special issue. Ultimately, highly interactive variants of peer assessment may have both advantages (e.g., through evoking highlevel argumentation) and disadvantages (e.g., through interrupting individual thought processes) on learning. It is certainly a task for future research to investigate when more interactive variants of peer assessments should be preferred over less interactive ones and vice versa.

Another issue for future research is how to successfully scaffold peer assessment (with whatever degree of interactivity) since high-level peer assessment processes will probably rarely show up spontaneously. Therefore, studies examining the effectiveness of different scaffolding and scripting techniques are of high importance. In this special issue, a number of scaffolding techniques have been described and/or studied (e.g., observation-based learning, 
see Van Steendam et al., THIS ISSUE; a-posteriori reflection forms, see Gielen et al., THIS ISSUE). Here as well, a cross-link to research on collaborative learning might be fruitful, as systematic approaches to scaffolding and scripting as well as empirical studies evaluating these forms of support can be found (Kollar, Fischer, \& Slotta, 2007; Quintana et al., 2004).

Finally, even though we have outlined a cognitive perspective on peer assessment, a comprehensive model on peer assessment should also incorporate motivational and emotional conditions, processes and outcomes. Studies as the one by Van Gennip et al. (THIS ISSUE) are important steps in this direction, particularly when studying the benefits and drawbacks in real educational scenarios in which motivational and emotional variables probably have a higher impact on learning than in the laboratory.

In this commentary we have pointed to some open questions of research on peer assessment. But no doubt: peer assessment is an important part of a shift towards more participatory forms of learning in our schools and universities. New, easily adaptable social technologies on the World Wide Web seem highly promising for facilitating the implementation of different peer assessment scenarios. The research approaches chosen or suggested in this special issue appear highly promising routes to study this increasingly relevant phenomenon. The findings of this collection of articles might form a strong basis future research can refer to and build on.

\section{References}

Aleven, V., Stahl, E., Schworm, S., Fischer, F., \& Wallace, R. (2003). Help seeking in interactive learning environments. Review of Educational Research, 73, 277-320.

Andriessen, J., Baker, M., \& Suthers, D. (2003). Argumentation, computer support, and the educational context of confronting cognitions. In J. Andriessen, M. Baker, \& D. Suthers (Eds.), Arguing to learn: Confronting cognitions in computer-supported collaborative learning environments (pp. 1-25). Dordrecht, the Netherlands: Kluwer.

Cho, K., \& MacArthur, C. (THIS ISSUE). Student revision with peer and expert reviewing. Learning and Instruction. PROVIDED BY ELSEVIER

Clark, H. H., \& Brennan, S. A. (1991). Grounding in communication. In L. B. Resnick, J. M. Levine, \& S. D. Teasley (Eds.). Perspectives on socially shared cognition (pp. 127-149). Washington, DC: American Psychological Association.

Gielen, S., Peeters, E., Dochy, F., Onghena, P., \& Struyven, K. (THIS ISSUE). Improving the effectiveness of peer feedback for learning. Learning and Instruction. PROVIDED BY ELSEVIER.

Graesser, A. C., Person, N. K., \& Magliano, J. P. (1995). Collaborative dialogue patterns in naturalistic one-on-one tutoring. Applied Cognitive Psychology, 9, 495-522.

Hattie, J., \& Timperley, H. (2007). The power of feedback. Review of Educational Research, 77, 81-112.

Hayes, J. R., \& Flower, L. S. (1980). Identifying the organization of writing processes. In L. W. Gregg \& E. R. Steinberg (Eds.), Cognitive processes in writing (pp. 3-30). Hillsdale, NJ: Erlbaum.

King, A. (1997). ASK to THINK - TEL WHY: A model of transactive peer tutoring for scaffolding higher level complex learning. Educational Psychologist, 32, 221-235.

King, A. (2007). Scripting collaborative learning processes: A cognitive perspective. In F. Fischer, I. Kollar, H. Mandl, \& J. M. Haake (Eds.), Scripting computer-supported collaborative learning: Cognitive, computational and educational perspectives (pp. 13-37). New York: Springer.

Kollar, I., Fischer, F., \& Slotta, J. D. (2007). Internal and external scripts in computersupported collaborative inquiry learning. Learning and Instruction, 17, 708-721. 
Leitão, S. (2000). The potential of argument in knowledge building. Human Development, 43, 332-360.

Nastasi, B. K., \& Clements, D. H. (1992). Social-cognitive behaviors and higher-order thinking in educational computer environments. Learning and Instruction, 2, 215-238.

Oser, F., \& Baeriswyl, F. (2001). Choreographies of teaching: Bridging instruction to learning. In V. Richardson (Ed.), Handbook of research on teaching (4th ed., pp. 1031-1065). Washington, DC: American Educational Research Association.

Quintana, C., Reiser, B. J., Davis, E. A., Krajcik, J., Fretz, E., Duncan, R. G., Kyza, E., Edelson, D., \& Soloway, E. (2004). A scaffolding design framework for software to support science inquiry. The Journal of the Learning Sciences, 13, 337-386.

Renkl, A. (1997). Learning from worked-out examples: A study on individual differences. Cognitive Science, 21, 1-29.

Schoenfeld, A. H. (1985). Mathematical problem solving. New York: Academic Press.

Strijbos, J. W., Narciss, S., \& Dünnebier, K. (THIS ISSUE). Peer feedback content and sender's competence level in academic writing revision tasks: Are they critical for feedback perceptions and efficiency? Learning and Instruction. PROVIDED BY ELSEVIER

Strijbos, J. W., Ochoa, T. A., Sluijsmans, D. M. A., Segers, M. S. R., \& Tillema, H. H. (2009). Fostering interactivity through formative peer assessment in (web-based) collaborative learning environments. In C. Mourlas, N. Tsianos, \& P. Germanakos (Eds.), Cognitive and emotional processes in web-based education: Integrating human factors and personalization (pp. 375-395). Hershey, PA: IGI Global.

Strijbos, J. W., \& Sluijsmans, D. M. A. (THIS ISSUE). Guest editorial - Unravelling peer assessment: Methodological, functional, and conceptual developments. Learning and Instruction. PROVIDED BY ELSEVIER

Van der Pol, J., Van den Berg, B. A. M., Admiraal, W. F., \& Simons, P. R. J. (2008). The nature, reception, and use of online peer feedback in higher education. Computers and Education, 51, 1804-1817.

Van Gennip, N. A. E., Segers, M. S. R., \& Tillema, H. H. (THIS ISSUE). Peer assessment as a collaborative learning activity: The role of interpersonal variables and conceptions. Learning and Instruction. PROVIDED BY ELSEVIER

Van Steendam, E., Rijlaarsdam, G., Sercu, L., \& Van den Bergh, H. (THIS ISSUE). The effect of instruction type and dyadic or individual emulation on the quality of higherorder peer feedback in EFL. Learning and Instruction. PROVIDED BY ELSEVIER

Van Zundert, M,, Sluijsmans, D., \& Van Merriënboer, J. (THIS ISSUE). Effective peer assessment processes: Research findings and future directions. Learning and Instruction. PROVIDED BY ELSEVIER

Webb, N. M. (1989). Peer interaction and learning in small groups. International Journal of Educational Research, 13, 21-39.

Webb, N. M., \& Farivar, S. (1999). Developing productive group interaction in middle school mathematics. In A. M. O'Donnell \& A. King (Eds.), Cognitive perspectives on peer learning (pp. 117-149). Hillsdale, NJ: Erlbaum. 